\title{
Analysis of Treatments of Adolescent Idiopathic Scoliosis
}

\author{
Jingyuan Zhang ${ }^{1^{*}}$, Ling $\mathrm{Li}^{2,+}$ \\ ${ }^{1}$ Wuhan Britain-China School, Wuhan, Hubei, 430000, email: mikezhang859@163.com \\ ${ }^{2}$ Zhejiang Chinese Medical University, Zhejiang, Hangzhou, 310053, email: 916108406@qq.com \\ + They are both first author.
}

\begin{abstract}
Adolescent idiopathic scoliosis (AIS) is an abnormal curvature of the spine that appears in late childhood or adolescence. Early treatment is critical for the prevention of the condition from becoming severe enough to require surgery. We compared the advantages and disadvantages of two treatment methods (i.e., bracing and yoga) for AIS treatment. After reviewing the protocol and the findings published in the journal article (about brace treatment) and the media article (about yoga treatment), we concluded that both methods were effective in the treatment of AIS, although each had its own weaknesses. Future studies need to explore whether the combination of bracing and yoga treatments could be more beneficial to AIS patients.
\end{abstract}

Keywords: Adolescent idiopathic scoliosis, scoliosis treatment, bracing, yoga

\section{INTRODUCTION}

\subsection{Topic Description}

Adolescent idiopathic scoliosis (AIS) is characterized by a lateral curvature of the spine with a Cobb angle of more than 10 degrees and vertebral rotation [1]. Symptoms of scoliosis typically include uneven shoulders and/or hips, bump in the lower back, numbness, weakness, or pain in the leg, trouble walking, trouble standing up straight, lethargy, shortness of breath and height loss [2]. According to the National Scoliosis Foundation, there are four million teenagers with scoliosis in US alone [3].

The definitive cause of scoliosis is unclear [4]. Thus, the effective treatment for scoliosis is not currently available. However, there are three main categories of attempts for the treatment of scoliosis, including surgery, bracing, and exercises [5]. The objective of all bracings is to restore the normal contours and alignment of the spine by means of external forces [1]. There are also different physical therapy methods, including yoga and Schroth methods [6]. Yoga has been widely used for AIS, because of its convenience and innocuous advantages [7].

\subsection{Background}

We have reviewed two articles, one from a scientific journal and another from a media source, regarding the treatment of scoliosis using bracing and yoga. The media article for bracing [8] presented different views about the effect of bracing from different groups, including parents, patients, and professional doctors. The journal article for bracing was written by Dr. Stuart Weinstein and his collaborators [1]. The study by Weinstein et al. was interventional, with 383 participants enrolled [1]. The authors intended to explore the effectiveness of bracing on treating scoliosis. Patients recruited were randomized to either bracing treatment (case group) or observation treatment (control group) [1]. The study was single masking with parallel assignment, lasting six years and seven months [1]. The journal article written by Loren $\mathrm{M}$. Fishman presented the effectiveness of isometric yoga and yoga-like poses for different scoliosis curve types [7]. They studied multiple avenues of yoga teaching, including in person studios and online through the Internet. The media article about yoga therapy mentioned that doing yoga poses everyday would improve spine curvature for AIS patients (Honor Whiteman, 2014).

To examine the effect and validity of each treatment, we analyzed and presented critiques on the above two studies involving yoga poses and bracing and explored 
the practicability of these methods in treating scoliosis. Meanwhile, the validity of policy addressed in the media article was also discussed and compared to formal scientific research.

\subsection{Research Question}

Our research question was to analyze the scientific evidence presented in media and scientific articles in terms of bracing and yoga treatments for scoliosis.

\section{METHODS}

\subsection{Data Sources}

The media article about bracing treatment was selected from the New York Times, a credible source for interviews and articles. Keywords like "bracing" and "scoliosis" were entered to find articles discussing the effect of bracing on scoliosis patients. As the media article was based on a research, the link for the research was found and the whole article was found on Google Scholar, also a widely used source for academic paper searching.

After browsing lots of news and articles in the media, we finally found that exercise therapy was also significant for AIS. After we located the key word "exercise", a media article on Medical News Today attracted our attention. It summarized the improvement of patients on spine curve by maintaining single yoga poses every day [9]. We subsequently found the original journal article mentioned in the media article.

\subsection{Data Extraction}

We extracted our evidence based on the content of journal article and its protocol. We summarized the results in several aspects, such as study type, population, aim, study duration, intervention, and outcome measurements.

\subsection{Critique and synthesis of evidence}

For the journal article on bracing and yoga treatment, we critiqued our evidence objectively, reporting the strengths and flaws of the evidences. In the critique, we compared content in the evidence with content in the course material to justify its soundness. Risk of bias tool was used in intention-to-treat group of bracing trial.

\section{RESULTS}

Table 1 below demonstrates the scientific evidences presented in journal articles in terms of bracing and yoga treatments for scoliosis. Table 1 is presented in the order of a trial, from design to outcome. The Findings for Risk of Bias Tolls are presented in Figures $\mathbf{1}$ and 2.

Table 1. Analysis and comparisons of the effects of braces and yoga on scoliosis treatment

\begin{tabular}{|c|c|c|}
\hline Parameters & Bracing Trial [1] & Yoga Trial [7] \\
\hline $\begin{array}{l}\text { Designed to assess the } \\
\text { outcomes of an intervention }\end{array}$ & Yes & Yes \\
\hline $\begin{array}{l}\text { Is the research question } \\
\text { 'focused' in terms of: } \\
\text { - Population (P) } \\
\text { - Intervention (I) } \\
\text { - Comparator (C) } \\
\text { - Outcomes (O) }\end{array}$ & $\begin{array}{l}\text { P: } 383 \text { patients, } 242 \text { follow } \\
\text { up } \\
\text { I: Bracing treatment, } \\
\text { different types according } \\
\text { to different prescription } \\
\text { centers } \\
\text { C: Patients who did not } \\
\text { wear braces } \\
\text { O: Only surrogate } \\
\text { outcome reported. No } \\
\text { final outcome. Both } \\
\text { primary and secondary } \\
\text { reported. }\end{array}$ & $\begin{array}{l}\text { P: Totally } 177 \text { AIS patients, } 75 \text { patients were } \\
\text { lost in follow-up x-rays and lack of } \\
\text { responses. } 56 \text { patients were recruited. } \\
\text { I: Three types of yoga poses for different } \\
\text { curves were taught through office/internet } \\
\text { C: Patients who did not do yoga-like poses, } \\
\text { no standard of care. } \\
\text { O: Surrogate outcome reported. Primary: } \\
\text { Blinded serial Cobb angles in coronal X- } \\
\text { rays } \\
\text { Secondary: Compliance of office and } \\
\text { Internet patients }\end{array}$ \\
\hline $\begin{array}{l}\text { How was randomization } \\
\text { carried out? Method } \\
\text { appropriate? }\end{array}$ & $\begin{array}{l}\text { Randomized, method is } \\
\text { appropriate for intention- } \\
\text { to-treat group }\end{array}$ & Nonrandomized, method is appropriate \\
\hline
\end{tabular}




\begin{tabular}{|c|c|c|}
\hline $\begin{array}{l}\text { Randomization sufficient to } \\
\text { eliminate systematic bias? }\end{array}$ & Yes & No \\
\hline $\begin{array}{l}\text { Allocation sequence } \\
\text { concealed from investigators } \\
\text { and participants? }\end{array}$ & No & No \\
\hline $\begin{array}{l}\text { Were losses to follow-up and } \\
\text { exclusions after } \\
\text { randomization accounted } \\
\text { for? }\end{array}$ & Yes & Yes \\
\hline Was the study stopped early? & Yes, for efficacy & No \\
\hline Cross-over between groups & No & No \\
\hline Baseline characteristics & $\begin{array}{l}\text { Baseline characteristics } \\
\text { were predefined. No } \\
\text { significant differences in } \\
\text { baseline characteristics } \\
\text { between each treatment } \\
\text { arm. The only two flaws } \\
\text { were the average height } \\
\text { between intention-to-treat } \\
\text { group and primary analysis } \\
\text { group; the other flaw was } \\
\text { that some baseline } \\
\text { characteristics were not } \\
\text { equalized, indicating } \\
\text { biased results. }\end{array}$ & $\begin{array}{l}\text { Baseline characteristics were predefined. } \\
\text { The Baseline characteristics were } \\
\text { predefined. he time of baseline and follow- } \\
\text { up x-rays were not consistent and led to a } \\
\text { long interval between them. Baseline, x-ray } \\
\text { pairs, versus follow-up were made into } \\
\text { cross-over analysis. } \\
\text { There were no significant differences in } \\
\text { baseline characteristics between the control } \\
\text { group and both curving types. }\end{array}$ \\
\hline $\begin{array}{l}\text { Were the participants 'blind' } \\
\text { to intervention they were } \\
\text { given? }\end{array}$ & No & No \\
\hline $\begin{array}{l}\text { Were the investigators 'blind' } \\
\text { to the intervention they were } \\
\text { giving to participants? }\end{array}$ & No & No \\
\hline $\begin{array}{l}\text { Were the people } \\
\text { assessing/analysing } \\
\text { outcome/s 'blinded'? }\end{array}$ & Yes & Yes \\
\hline $\begin{array}{l}\text { Were there any differences } \\
\text { between the study groups } \\
\text { that could affect the } \\
\text { outcome/s? }\end{array}$ & $\begin{array}{l}\text { Not significantly, only in } \\
\text { heights }\end{array}$ & $\begin{array}{l}\text { Not significantly. Two groups are not } \\
\text { balanced }\end{array}$ \\
\hline $\begin{array}{l}\text { Clearly defined study } \\
\text { protocol? }\end{array}$ & Yes & No \\
\hline $\begin{array}{l}\text { Were the follow-up intervals } \\
\text { the same for each study } \\
\text { group? }\end{array}$ & Yes & Yes \\
\hline Selective reporting of data? & Some, in interim analyses & Some, in reporting yoga exercises condition \\
\hline
\end{tabular}




\begin{tabular}{|c|c|c|}
\hline $\begin{array}{l}\text { Was a power calculation } \\
\text { undertaken? }\end{array}$ & $\begin{array}{l}\text { Type I error reported. Each } \\
\text { arm was powered at } 90 \%\end{array}$ & $\begin{array}{l}\text { Type I error reported. Each arm was } \\
\text { powered at } 95 \% \text {. }\end{array}$ \\
\hline Unsupported conclusion? & No & No \\
\hline $\begin{array}{l}\text { Were the results reported for } \\
\text { each outcome in each study } \\
\text { group at each follow-up } \\
\text { interval? }\end{array}$ & Reported in detail & Not mentioned \\
\hline $\begin{array}{l}\text { Was there any missing or } \\
\text { incomplete data? }\end{array}$ & Yes, in follow up & Yes, in follow up \\
\hline Critically discussed? & Yes & Yes \\
\hline Statistical tests were used? & $\begin{array}{l}\text { Linear regression and } \\
\text { statistical measurements } \\
\text { and mathematical } \\
\text { modeling were used to } \\
\text { help researchers eliminate } \\
\text { the effect of confounding } \\
\text { variables. }\end{array}$ & $\begin{array}{l}\text { Paired t-tests, } \chi 2 \text {, and Mann-Whitney } U \\
\text { were used to analyze curve angles. } \\
\text { The indicator could represent curving } \\
\text { angles objectively. }\end{array}$ \\
\hline$P$ values reported? & $\begin{array}{l}\text { Yes, p-value for stopping } \\
\text { the study was } 0.00821 .\end{array}$ & $\begin{array}{l}\text { Yes, } p \text {-value for evaluating significance of } \\
\text { age, Risser number, curve type were } \\
\text { greater } 0.05 \text {, other } p \text {-values were less than } \\
0.05 \text {. }\end{array}$ \\
\hline $\begin{array}{l}\text { Confidence intervals (Cls) } \\
\text { reported? }\end{array}$ & $95 \%$ & No \\
\hline $\begin{array}{l}\text { Size of the intervention or } \\
\text { treatment effect? }\end{array}$ & 139 bracing & 41 yoga \\
\hline $\begin{array}{l}\text { Appropriateness of table and } \\
\text { data? }\end{array}$ & $\begin{array}{l}\text { Data were reported } \\
\text { precisely in the table. } \\
\text { Uncertainty was reported } \\
\text { in the table. } \\
\text { Contrast between baseline } \\
\text { and follow-up study was } \\
\text { shown clearly. }\end{array}$ & $\begin{array}{l}\text { Data were reported precisely in the table. } \\
\text { Contrast between baseline and follow-up } \\
\text { study was shown clearly. } \\
\text { Table was a cross-over graph, easy to } \\
\text { analyze and compare. }\end{array}$ \\
\hline Adverse events reported? & Yes & No \\
\hline $\begin{array}{l}\text { Interim analysis } \\
\text { effectiveness? }\end{array}$ & $\begin{array}{l}\text { Patients were analyzed } \\
\text { every six months; the data } \\
\text { were determined by } \\
\text { clinician inspection and } \\
\text { self-reporting. }\end{array}$ & $\begin{array}{l}\text { Patients were followed up by item of self- } \\
\text { report per month. }\end{array}$ \\
\hline Placebo effect? & No & No \\
\hline $\begin{array}{l}\text { Cost-effectiveness analysis } \\
\text { undertaken? }\end{array}$ & Can't tell & Yes. Yoga is an economic choice. \\
\hline
\end{tabular}




\begin{tabular}{|c|c|c|}
\hline $\begin{array}{l}\text { Any outcomes you would } \\
\text { have wanted information on } \\
\text { that have not been studied } \\
\text { or reported? }\end{array}$ & Yes & Yes \\
\hline $\begin{array}{l}\text { Are you able to disinvest } \\
\text { resources in one or more } \\
\text { existing interventions in order } \\
\text { to be able to re-invest in the } \\
\text { new intervention? }\end{array}$ & No & No \\
\hline Publication crisis? & No & No \\
\hline Registration? & $\begin{array}{l}\text { Yes. The study was } \\
\text { registered for the BrAIST } \\
\text { research group but not } \\
\text { specific research. }\end{array}$ & $\begin{array}{l}\text { No. The study was registered for follow up } \\
\text { studies }\end{array}$ \\
\hline Headlines? & Normal headlines & Normal headlines \\
\hline Ethics? & $\begin{array}{l}\text { Written consent form was } \\
\text { collected by the research } \\
\text { group to ensure that } \\
\text { parents or guardians of } \\
\text { the kids were aware of the } \\
\text { treatment and fully agreed } \\
\text { with the treatment. } \\
\text { When a patient did not } \\
\text { comply with the brace, } \\
\text { adverse events might } \\
\text { occur so negative effects } \\
\text { on treatment took place. } \\
\text { Meanwhile, it was not } \\
\text { ethical to make this } \\
\text { statement as researchers } \\
\text { had to be responsible for } \\
\text { the health of patients, or } \\
\text { this condition was } \\
\text { specified in the consent } \\
\text { form which did not } \\
\text { expand. }\end{array}$ & $\begin{array}{l}\text { Consent form was mentioned in the study, } \\
\text { which was required. Patients' willingness to } \\
\text { do yoga was mentioned in the required } \\
\text { consent form. Patients were required to } \\
\text { have initial X-rays before starting daily yoga } \\
\text { for } 5 \text { months, and finally received second X- } \\
\text { rays afterwards. Safety events were not } \\
\text { taken into account in the whole experiment. } \\
\text { Patients may face potential harm from } \\
\text { radiation effects. }\end{array}$ \\
\hline Correlation and causation? & $\begin{array}{l}\text { Positive correlation was } \\
\text { well established between } \\
\text { wearing time and } \\
\text { treatment effect. } \\
\text { Confounding factor } \\
\text { includes distractive factors } \\
\text { in measuring temperature }\end{array}$ & $\begin{array}{l}\text { Association was established. Confounding } \\
\text { factors include self-reporting. }\end{array}$ \\
\hline
\end{tabular}




\begin{tabular}{|c|c|c|}
\hline Conflicts of interest? & $\begin{array}{l}\text { No potential conflicts of } \\
\text { interest with respect to the } \\
\text { research, authorship, } \\
\text { and/or publication of this } \\
\text { article. }\end{array}$ & $\begin{array}{l}\text { No potential conflicts of interest with } \\
\text { respect to the research, authorship, and/or } \\
\text { publication of this article. }\end{array}$ \\
\hline Could be replicated? & $\begin{array}{l}\text { No, because race/ethnicity } \\
\text { and other factors were not } \\
\text { controlled }\end{array}$ & $\begin{array}{l}\text { Not mentioned in the study. Yoga was } \\
\text { rather subjective and the sample was small. } \\
\text { From the perspective of the author, the } \\
\text { study could not be replicated. }\end{array}$ \\
\hline Peer Review? & Not mentioned & Not mentioned \\
\hline Spinned? & No & No \\
\hline Sample size? & $\begin{array}{l}\text { While only } 383 \text { patients } \\
\text { were enrolled in the study, } \\
\text { the sample size was not } \\
\text { large enough to deduce } \\
\text { convincing results. In later } \\
\text { phases of study, sample } \\
\text { size had to be enlarged to } \\
\text { achieve fully application } \\
\text { for bracing in markets. }\end{array}$ & $\begin{array}{l}\text { Totally } 177 \text { AIS patients were enrolled in the } \\
\text { Manhattan clinic, } 75 \text { patients were lost in } \\
\text { follow-up x-rays and lack of responses. } \\
\text { While } 56 \text { patients were recruited, the } \\
\text { sample size was not large enough to } \\
\text { deduce convincing results. }\end{array}$ \\
\hline
\end{tabular}

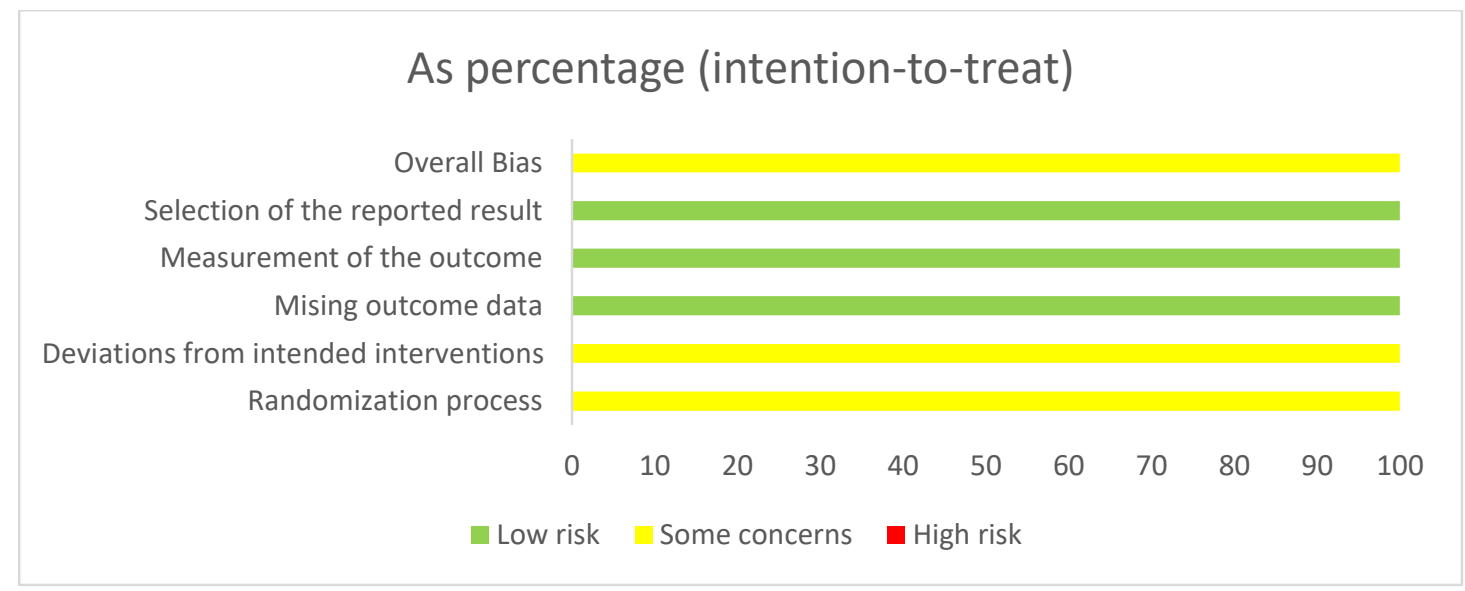

Figure 1. Risk of bias tool analysis of randomized brace trial

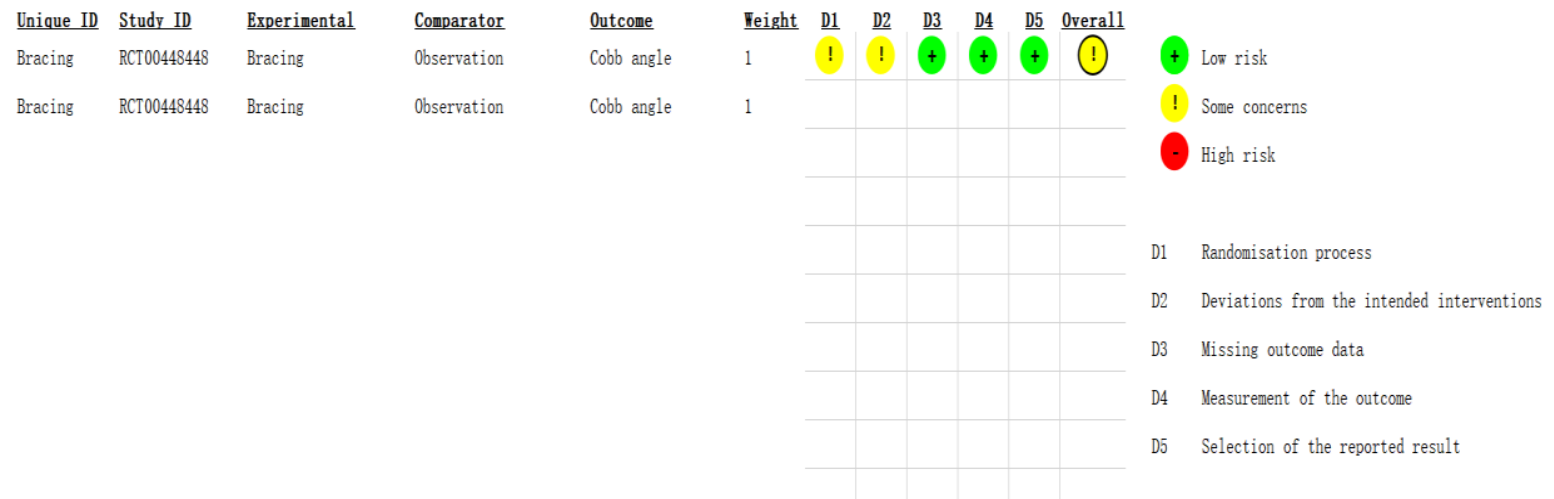

Figure 2. Risk of bias tool analysis of randomized brace trial 


\section{DISCUSSION}

\subsection{Policy Context}

Bracing has been shown to be effective in treating scoliosis [1]. However, more studies have to be done to determine the effect of braces on specific groups such as race and ethnicity. Besides, differences among braces in different centers have to be taken into account to determine what kinds of brace would yield optimum results in treating scoliosis [1]. Currently, the field of bracing ought to solve problems related to flaws of the study to clarify actual effect of braces on patients.

The study of yoga exercise shows great potential as an innocuous, efficient and simple therapy in early stage of adolescent idiopathic scoliosis, especially among adolescent girls [7]. Patient's pride and sense of competence increased as their curves decreased [7]. Because the intervention was simple, time-saving and painless, it did not have strong obstacles to compliance. Relevant research was performed on the disease background, transmitted methods and so on. Besides, a bigger number of cases was required, and were adverse to statistical analysis of the data. A deeper study on quantification of study duration or frequency of yoga poses is needed, and the safety events should be mentioned in the article.

\subsection{Correlation between media and journal articles}

According to the journal article, benefits of bracing for kids have been testified [1]. As a result, claims against braces in the media article were refuted. However, some of the refuters posed questions that the effect of bracing on kids is not obvious, which also arises as a phenomenon in the experiment. Authors of the journal did not elaborate on whether bracing had different effects of different groups, which was identified by Erika Schumaker in the media article [1]. Meanwhile, Becky Houser mentioned in the media article that randomizing kids to observation treatment is not ethical either, which is also not addressed by the author of the journal article [8].

The journal article on yoga covered most of claims in the media and had deeper studies on different yoga and yoga-like poses for three types of scoliotic curve [7]. The media article suggested that the benefits of yoga for other health problems, such as anxiety and depression in expectant mothers and lower blood pressure, which was supported by the journal article [9].

\subsection{Strengths and weaknesses of articles}

The strength for bracing research [1] relies mainly in the rigorous selection criteria and censorship by different organizations and committees, mathematical analysis and modeling, using different indicators to represent parameters instead of self-reporting. The flaw of the research mainly lies in small sample size, reporting bias, unequal sample size and uncontrolled activity for observation groups and brace categories.

The trial of yoga treatment for scoliosis [7] has the following strengths: (1) It was an innocuous, simple, high compliance and almost costless trial; (2) Research question was clear and practical and the endpoints were appropriate; (3) The outcome assessor was blinded, which can limit general bias; (4) The intervention did not have strong obstacles to compliance; (5) the findings were generalizable to usual patients and settings: adequate eligibility criteria; and (6) Relevant research was performed on the disease background, transmitted methods.

There are some weaknesses about the yoga study reported in the journal article [7]: (1) The sample size was too small; (2) This trial was not registered and the reliability need to be confirmed; (3) It was a nonrandomized trial, which lead to the imbalance between two groups and may increase the chance of confounding; (4) The article had no plan to do further quantification of study duration or frequency, the time of periodic follow-up was not specific and unified; (5) Compliance was evaluated only by a method of selfreport, patients may tell what doctors were expected; and (6) Safety events of yoga and yoga-like poses were not mentioned.

\subsection{Limitations}

The largest limitation in our research is that we examined only one paper per topic. Thus, different views in each treatment are not counted. Though the research we examined have been cited over 400 times, biases still exist and ought to be answered by other researches. Secondly, the resources we analyzed are limited in depth. For the specific BRAIST research, we have only examined its information on protocol, clinical government website and journal article. In order to fully examine the research work, interview with conductor of the research and further information are necessary. Thirdly, sophisticated mathematical analyzing tools were not utilized in our study. Finally, although logical regression $\mathrm{p}$ values were generated in our study, we do not have enough capability to examine its correctness.

\subsection{Future Work}

To fully examine the research of the above two journal articles, more information has to be reviewed from other researches taken by BrAIST (Bracing in Adolescent Idiopathic Scoliosis trial) [1]. Appropriate mathematical analysis tools have to be utilized in the research to examine the soundness of correlation between different data. More researches in the field of treatment for scoliosis have to be reviewed in order to gain a wider 
view towards the whole field. Thus, more valid conclusions could be met by comparing different trials. Since both methods are positive to treating scoliosis, we could further research on methods which combine bracing treatment and yoga treatment, which could be more beneficial to patients.

\section{CONCLUSIONS}

We chose the topic based on our personal experience and interests. Pros and cons for specific types of treatments of scoliosis are also hotly debated in the field of scoliosis. Media and journal articles were chosen from credible sources.

Though with certain flaws, both journal articles exhibit positive effects of bracing treatment and yoga treatment on scoliosis. In the process of examination, we carefully reviewed both articles and protocols, and formed critiques on certain evidence extracted from these two sources. Correlation between media and journal article has also been discussed. Considering existing context, more work should be done by us to fully examine the effect of bracing and yoga treatment different categories of patients.

\section{REFERENCES}

[1] Weinstein, S.L., Dolan, L.A., Wright, J.G., and Dobbs, M.B. (2013). Effects of bracing in adolescents with idiopathic scoliosis. N Engl J Med 369, 1512-1521.

[2] Felson, S. (2020). What are the Symptoms of Scoliosis? https://www.webmd.com/backpain/what-are-the-symptoms-of-scoliosis.

[3] Center, S.R. (2019). How Common is Scoliosis? https://www.scoliosisreductioncenter.com/blog/ho $\mathrm{W}$-common-is-scoliosis.

[4] Parent, S., Newton, P.O., and Wenger, D.R. (2005). Adolescent idiopathic scoliosis: etiology, anatomy, natural history, and bracing. Instr Course Lect 54, 529-536.

[5] Website, T.N. (2017). Scoliosis - Treatment in adults.

https://www.nhs.uk/conditions/scoliosis/treatmentin-adults/.

[6] Medicine, J.H. (2021). Schroth Method for Scoliosis.

https://www.hopkinsmedicine.org/health/conditions -and-diseases/scoliosis/schroth-method-forscoliosis.

[7] Fishman, L.M. (2021). Isometric Yoga-Like Maneuvers Improve Adolescent Idiopathic Scoliosis-A Nonrandomized Control Trial. Glob Adv Health Med 10, 2164956120988259.
[8] Times, N.Y. (2013). Study Affirms Benefit of Back Braces as Scoliosis Treatment. https://www.nytimes.com/2013/09/20/health/newstudy-lends-conclusive-support-to-a-scoliosistreatment.html.

[9] Today, M.N. (2021). A single yoga pose each day may improve spine curvature for scoliosis patients. https://www.medicalnewstoday.com/article/283689 